\title{
From the lab to the river: Determination of ecological hosts of Anodonta anatina
}

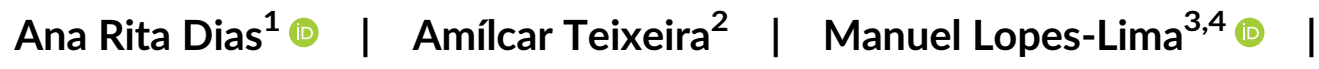 \\ Simone Varandas ${ }^{5}$ | Ronaldo Sousa ${ }^{1}$
}

${ }^{1}$ Centre of Molecular and Environmental Biology (CBMA), Department of Biology, University of Minho, Braga, Portugal

${ }^{2}$ Centro de Investigação de Montanha (CIMO), Instituto Politécnico de Bragança, Bragança, Portugal

${ }^{3}$ Centro de Investigação em Biodiversidade e Recursos Genéticos (ClBIO)/Instituto Nacional de Biodiversidad (InBIO), University of Porto, Vairão, Portugal

${ }^{4}$ Centro Interdisciplinar de Investigação Marinha e Ambiental (CIIMAR), University of Porto, Matosinhos, Portugal

${ }^{5}$ Centro de Investigação e Tecnologias Agroambientais e Biológicas (CITAB), University of Trás-os-Montes and Alto Douro (UTAD), Vila Real, Portugal

\section{Correspondence}

Ana Rita Dias, CBMA - Centre of Molecular and Environmental Biology, Department of Biology, University of Minho, Campus Gualtar, 4710-057, Braga, Portugal.

Email: ritads.dias@gmail.com

\section{Funding information}

Fundação para a Ciência e a Tecnologia, Grant/ Award Number: PTDC/AGRFOR/1627/2014

\section{Abstract}

1. Coextinction is the simplest form of secondary extinction and freshwater mussels (Bivalvia, Unionida) may be particularly prone to this phenomenon as their life cycle includes an obligatory parasitic larval stage on fish hosts.

2. The main aims of this study were to determine the possible ecological fish hosts of Anodonta anatina (Linnaeus, 1758) in several rivers of the Douro basin in northern Portugal and to assess possible spatial and temporal differences in glochidial (larval) loads. In order to achieve this, electrofishing was conducted from December to April, the fish fauna was characterized, and levels of infestation with A. anatina glochidia were determined.

3. Native cyprinid species, mainly Luciobarbus bocagei (Iberian barbel) and Squalius carolitertii (northern Iberian chub), together with the non-native Lepomis gibbosus (pumpkinseed sunfish) and Alburnus alburnus (common bleak), were found to have the highest glochidial loads. Clear differences in infestation between rivers and throughout time were detected, with an infestation period from January to March, and with the Tâmega River having the highest prevalence.

4. Anodonta anatina is able to infest a variety of fish species, and this together with earlier studies showed that the metamorphosis into juveniles occurs mainly in native cyprinid species, although non-native species like common bleak can also be considered suitable hosts. However, the larvae infesting other non-native species, such as the pumpkinseed sunfish, do not metamorphose and can be considered 'dead ends'.

5. Overall, the results reported here are important for the conservation of A. anatina (and other unionoid species) because several Iberian rivers (and worldwide) have been subjected to the extirpation of native fish species and the introduction of non-native fish species. Therefore, careful assessments of fish communities should be conducted to assess possible negative interactions with freshwater mussels.

\section{KEYWORDS}

coextinction, conservation, fish, freshwater mussels, glochidia, infestation 


\section{1 | INTRODUCTION}

Coextinction is considered the simplest form of secondary extinction (Brodie et al., 2014), and is defined as the extinction of a species (e.g. a parasite) as a consequence of the disappearance or drastic population decline of another species (e.g. its host) (Colwell, Dunn, \& Harris, 2012; Koh et al., 2004). Documenting coextinctions is complicated owing to knowledge gaps about the specificity of hosts, limitations in the historical collections, incomplete systematics of affiliated taxa, and the almost complete lack of quantitative experimental studies (Brodie et al., 2014; Colwell et al., 2012). In addition to the challenges of documenting coextinctions, this phenomenon can be significantly influenced by human disturbance such as pollution, loss, and fragmentation of habitat, overexploitation, climate change, and the introduction of non-native species (Dunn, Harris, Colwell, Koh, \& Sodhi, 2009; Koh et al., 2004). These human disturbances not only add complexity to any effort to reduce the risk of coextinction but also complicate the documentation of causes for its occurrence (Colwell et al., 2012). Some known examples of coextinctions or imminent coextinctions include the louse Felicola (Lorisiola) isidoroi (Perez \& Palma, 2001), which appears to be a specific parasite of the Iberian lynx, Lynx pardinus (Temminck, 1827) (Perez \& Palma, 2001), and Neotrichodectes sp. (Ewing, 1929), which may have become extinct when the population of the ferret Mustela nigripes (Audubon \& Bachman, 1851) drastically declined or when the last wild ferrets were sterilized for later reproduction in captivity (Dunn, 2005).

In aquatic ecosystems, freshwater mussels (Bivalvia: Unionida) might also represent an example of coextinction (Barnhart, Haag, \& Roston, 2008). Freshwater mussels are one of the most threatened faunal groups worldwide (Lopes-Lima et al., 2014; 2018; Lydeard et al., 2004; Strayer et al., 2004), and this in part results from some of their biological characteristics (Ferreira-Rodríguez et al., 2019). For example, freshwater mussels need an obligatory host, usually a fish or in rare cases an amphibian (Modesto et al., 2018). This parasitic phase could be advantageous for nutrition and growth, but also for dispersal, by providing the possibility to disperse upstream (Barnhart et al., 2008). Nevertheless, it also represents a higher risk of coextinction because the mussels are completely dependent upon their hosts to complete their life cycle. Despite this, very few studies have quantitatively reported the decline or extinction of fish hosts and the implications for freshwater mussel species (Modesto et al., 2018).

In recent years it has been recognized that a species or population coextinction has immediate implications for local management and conservation decisions (Koh et al., 2004), with the evaluation of host specificity in freshwater mussels required to facilitate prioritization for the risk of extinction and for implementing conservation measures (Ferreira-Rodríguez et al., 2019; Modesto et al., 2018). For example, Spooner, Xenopoulos, Schneider, and Woolnough (2011) modelled the effects of the expected reduction in river flow (considering present and future climate-change scenarios) on the extinction of mussel species in the rivers of the eastern USA, predicting that up to $43 \%$ of the mussel populations might disappear as a result of the loss of their fish host populations. Thus, possible conservation strategies directed at these organisms must always include the management of the native fish fauna (e.g. ex situ propagation programmes for the reintroduction and augmentation of extirpated or declining populations; FerreiraRodríguez et al., 2019).

This study used as a model organism the duck mussel, Anodonta anatina (Linnaeus, 1758), which is widespread in Europe and Asia, from the Iberian Peninsula in the south to Scandinavia in the north and Russia in the east (Froufe et al., 2014; Graff, 2007; Lopes-Lima et al., 2016). This is a generalist species in terms of habitat choice, colonizing both lentic and lotic habitats, from small streams to large rivers, lakes, and reservoirs (Froufe et al., 2014; Lopes-Lima et al., 2016). Although A. anatina is still considered a common species in Europe, there is some ignorance regarding its ecology (e.g. abundance, distribution, reproduction, and population structure; Hinzmann et al., 2013). At present, population declines have been documented throughout Europe: this species is listed as threatened and protected in Germany, for example (Lopes-Lima, 2014). The larvae (glochidia) of A. anatina are large and hooked, and the species is considered a generalist using a wide spectrum of fish hosts (Bauer, 2001). Recent studies conducted in the Iberian Peninsula and Central Europe, however, suggest a narrower spectrum of hosts that is usually restricted to native fishes, mainly cyprinids (Douda et al., 2013). Little is known about its compatibility with non-native species that have recently been introduced, but a recent study showed that Ctenopharyngodon idella (Valenciennes, 1844) was one of the best hosts among the species tested (Huber \& Geist, 2019). Despite these contradictory findings (i.e. whether or not non-native fish species are good hosts), there is a risk that $A$. anatina and other unionid species considered as host generalists might be incapable of using many of the non-native species available in the fish community. In this case, biotic homogenization (Rahel, 2002) would have a great impact on the maintenance and conservation of freshwater mussels (Douda et al., 2013).

Studies that aim to determine host specificity of freshwater mussels are mostly based on laboratory experiments (Ćmiel, Zając, Lipińska, \& Zając, 2018; Douda, Vrtílek, Slavík, \& Reichard, 2011; Haag \& Warren, 1997; Taeubert, Gum, \& Geist, 2011). These ex situ determinations need to be validated in situ for three main reasons: (i) it is impossible to replicate in the laboratory all of the biotic and abiotic factors that can potentially affect the infestation of potential hosts; (ii) it is necessary to check whether the laboratory-tested hosts co-occur in natural environments at the time that freshwater mussel glochidia are discharged; and (iii) it is important to verify whether these hosts are adequate, including the determination of glochidial loads (number of glochidia per fish), and to assess the viability of the glochidia in each host species. As the freshwater fish fauna of the Iberian Peninsula is distinct from that of the rest of Europe, with about $80 \%$ of the species belonging to the Cyprinidae family being endemic (Almaça, 1995; Clavero \& García-Berthou, 2006), the main aims of this study were to determine in situ the fish hosts of $A$. anatina in five basins in northern Portugal and to assess possible spatial and temporal differences in glochidial loads. We hypothesize that native cyprinid species are the main fish hosts and a marked temporal trend in the infestation will be detected. This information is vital for the 
future conservation of $A$. anatina as any management measure cannot be applied without basic ecological data on their reproductive cycle.
(Linnaeus, 1753) (black poplar), and Salix atrocinerea (Brot., 1804) (grey willow), among other species.

\section{2 | MATERIALS AND METHODS}

\section{1 | Study area}

The study area is part of the Douro River basin located in northern Portugal, and included sampling sites in the Tua, Sabor, Paiva, Corgo, and Tâmega rivers (Figure 1). All five rivers have total lengths between 47 and $165 \mathrm{~km}$ and are subjected to different hydrological conditions, climate, and human disturbance, including the presence of several dams that restrict connectivity (for a detailed description see Sousa et al., 2012). The landscape includes plateaux, mountains, and embedded valleys, with different land uses such as industry, urban development, agriculture, and forestry. The Corgo, Tua, and Tâmega rivers are subjected to higher levels of human disturbance, mainly by pollution from the surrounding industries and urban areas, compared with the Sabor and Paiva rivers (Meira et al., 2019; Sousa et al., 2013, 2019); however, all sites surveyed in this study are at least of 'good ecological status' (Alencoão \& Pacheco, 2006; Claro, 2010; Meira et al., 2019; Portilho, 2013; Silva, 2010; Sousa et al., 2012, 2013) under the European Water Framework Directive (Council of the European Communities, 2000). The riparian vegetation at all sites mainly comprises Alnus glutinosa (L.) Gaertner, 1790 (common alder), Fraxinus angustifolia (Vahl, 1804) (narrow-leafed ash), Populus nigra

\section{2 | Sampling}

To determine the ecological hosts of A. anatina, one site was selected in the Corgo, Tâmega, Paiva, Tua, and Sabor rivers (Figure 1). Sampling occurred between December 2016 and April 2017, on 6 December, 9 January, 31 January, 14 February, 9 March, and 4 April. The chosen sampling period covered the release of the glochidia by $A$. anatina (Hinzmann et al., 2013). At every site and date (except for 9 January 2017), abiotic data such as temperature, conductivity, and total dissolved solids (TDS) were measured using a multiparametric probe (Hach HQ40D multimeter; Hach, Loveland, CO). Fish were captured using a Hans Grassl II ELT (300/600 V) electrofishing device (Hans Grassl GmbH, Schönau am Königssee, German) for approximately $30 \mathrm{~min}$ and within an area of approximately $250 \mathrm{~m}^{2}$. Fishing effort was higher near the banks, the preferred habitat of $A$. anatina in the rivers studied (Hinzmann et al., 2013; Sousa et al., 2012). Fish composition, abundance (total catch per unit of effort for 15 min of fishing, ind. CPUE) and biometric data (total length and weight) were collected at each site and period. A random subsample of 10-15 individuals per species was collected for posterior observation under a stereoscope in the laboratory, with the remaining fishes returned to the river. In the laboratory, glochidia were inspected and counted, mainly on the fins and gills. For gills, the operculum was removed to facilitate the

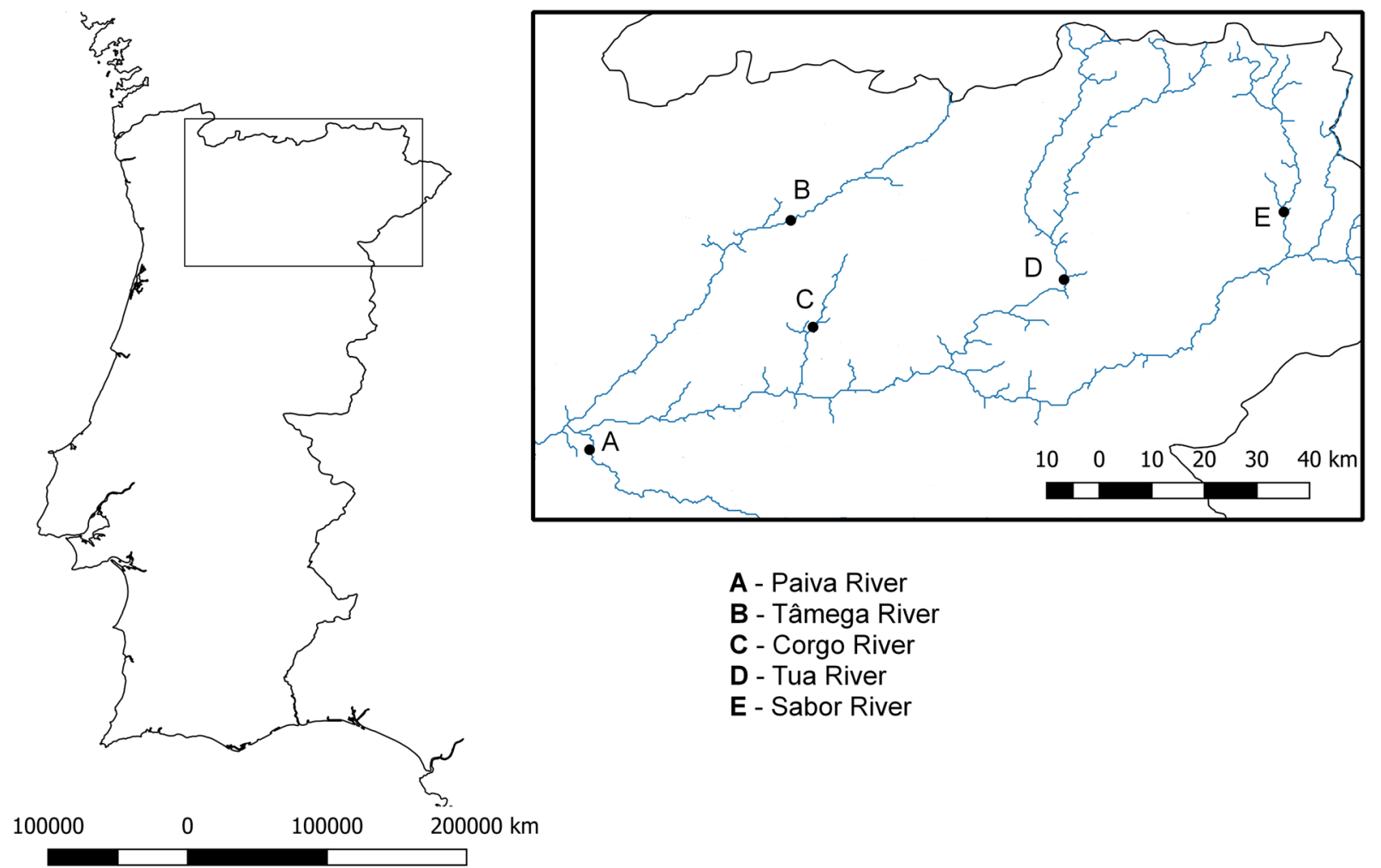

FIGURE 1 Map of the study area showing the location of the five sites 
observation. The abundance of $A$. anatina was assessed by snorkelling in 5-min periods replicated six times by two different researchers during June 2017. At each site, a river stretch with a total length of $250 \mathrm{~m}$ was surveyed covering all available habitat types (i.e. riffle, pool, centre of the channel, and banks), following the method described by Sousa et al. (2018). Abundance was expressed as the total catch per unit of effort for 5 min of diving (ind. CPUE).

\section{3 | Data analysis}

To assess possible differences in fish communities across sites and time, a non-metric multidimensional scaling (nMDS) was performed using the Bray-Curtis similarity index based on the abundance data previously transformed with the square root. A three-way PERMANOVA (permutational multivariate analysis of variance) was used to test the simultaneous response of one or more variables to one or more factors in an experimental design, like ANOVA, using permutational methods (Anderson, 2001). The statistical significance of variance $(\alpha=0.05)$ was tested using 9999 permutations. When the number of permutations was lower than 150 the Monte-Carlo $P$-value $\left(P_{\mathrm{MC}}\right)$ was considered. The response of the variable number of glochidia to three distinct factors was tested: fish species (with nine levels - one for each species recorded); date (with six levels 6 December, 9 January, 31 January, 14 February, 9 March, and 4 April); and site (with five levels - Corgo, Tâmega, Paiva, Tua and Sabor rivers), using the Euclidian distance matrices. Kendall's correlation tests were also performed between fish size and the number of glochidia, and between the number of glochidia and the abundance of A. anatina, using only the data from the date when the highest number of glochidia was found at each site. Differences in the observed counts of fish infested with glochidia from the expected counts of fish species collected in the field (i.e. to evaluate whether A. anatina had a preference for a fish host) were assessed by a G-test of goodness of fit. Again, the data used corresponded to the dates where the maximum number of glochidia was observed for each site. Differences in the average abundance of $A$. anatina between sites were assessed by a Kruskal-Wallis test. The Kendall's correlation and G-tests were conducted using R 3.2.2 (R Core Team, 2017) with the packages GGPLOT2 (Wickham, 2009) and HMISC (Harrell, 2015). The nMDS, PERMANOVA, and subsequent pairwise tests were conducted in PRIMER 6.1.6 (PRIMER-E Ltd., Plymouth, UK) with the PERMANOVA + 1.0.1 add-on (Anderson, Gorley, \& Clarke, 2008).

\section{3 | RESULTS}

\subsection{Abiotic conditions and fish communities sampled}

During the sampling period, water temperature ranged between 5.4 (Sabor River, 6 December) and $14.6^{\circ} \mathrm{C}$ (Paiva River, 4 April), TDS ranged between 14 (Paiva River, 14 February) and $70 \mathrm{mg} \mathrm{L}^{-1}$ (Sabor
River, 6 December), and conductivity ranged between 30.2 (Paiva River, 14 February) and $151.0 \mu \mathrm{S} \mathrm{cm}^{-1}$ (Sabor River, 6 December).

The fish fauna comprised nine species: four species are considered native and five are introduced, one from southern Portugal and four that are non-native (Table 1). The minimum number of species collected was five in the Paiva River and the maximum number was eight in the Corgo and Sabor rivers. All rivers, except the Sabor and Paiva rivers, contain distinct fish communities (pseudo $F=8.28$; $P<0.001$ ) (Figure 2).

\section{2 | Determination of glochidial loads and the main ecological hosts}

In the Sabor and Tâmega rivers, infestation peaked on 31 January, whereas in the Corgo, Paiva, and Tua rivers infestation peaked on 14 February. Luciobarbus bocagei (Iberian barbel) and Squalius carolitertii (northern Iberian chub) were the species with higher glochidial loads (pseudo $F=2.98 ; P=0.003$ ) (Table S1). The PERMANOVA tests were significant for all factors (location (lo) pseudo $F=26.46, P=0.003$; date (da) pseudo $F \approx 17.03$, $P=0.001$; and fish species (sp) pseudo $F=3.50, P=0.045)$ and for all interactions among factors (lo $\times$ da pseudo $F=7.62, P=0.004$; lo $\times \mathrm{sp}$ pseudo $F=4.78, P=0.01$; da $\times$ sp pseudo $F=2.62, P=0.022$; lo $\times$ da $\times$ sp pseudo $F=2.98, P=0.003$ ).

In the Corgo River, chub and Squalius alburnoides (calandino) had the highest glochidial loads on 31 January and 9 March, respectively, with a maximum average of approximately nine glochidia per fish. Some glochidia were found on Pseudochondrostoma duriense (nase), Lepomis gibbosus (pumpkinseed sunfish), and Gobio lozanoi (Pyrenean gudgeon).

TAB LE 1 Taxonomy and native/non-native classification of all species captured at all sites during the sampling period

\begin{tabular}{|c|c|c|}
\hline Common name & Species name & Classification \\
\hline Calandino & $\begin{array}{l}\text { Squalius alburnoides } \\
\text { (Steindachner, 1866) }\end{array}$ & Native \\
\hline $\begin{array}{l}\text { Northern } \\
\text { straight-mouth } \\
\text { nase }\end{array}$ & $\begin{array}{l}\text { Pseudochondrostoma duriense } \\
\text { (Coelho, 1985) }\end{array}$ & Native \\
\hline Iberian barbel & $\begin{array}{l}\text { Luciobarbus bocagei } \\
\text { (Steindachner, 1864) }\end{array}$ & Native \\
\hline $\begin{array}{l}\text { Northern Iberian } \\
\text { chub }\end{array}$ & $\begin{array}{l}\text { Squalius carolitertii (Doadrio, } \\
\text { 1988) }\end{array}$ & Native \\
\hline $\begin{array}{l}\text { Southern Iberian } \\
\text { spined loach }\end{array}$ & Cobitis paludica (Buen, 1930) & Non-native \\
\hline $\begin{array}{l}\text { Eastern } \\
\text { mosquitofish }\end{array}$ & $\begin{array}{l}\text { Gambusia holbrooki (Girard, } \\
\text { 1859) }\end{array}$ & Non-native \\
\hline $\begin{array}{l}\text { Pumpkinseed } \\
\text { sunfish }\end{array}$ & $\begin{array}{l}\text { Lepomis gibbosus (Linnaeus, } \\
\text { 1758) }\end{array}$ & Non-native \\
\hline Pyrenean gudgeon & $\begin{array}{l}\text { Gobio lozanoi (Doadrio \& } \\
\text { Madeira, 2004) }\end{array}$ & Non-native \\
\hline Common bleak & $\begin{array}{l}\text { Alburnus alburnus (Linnaeus, } \\
\text { 1758) }\end{array}$ & Non-native \\
\hline
\end{tabular}




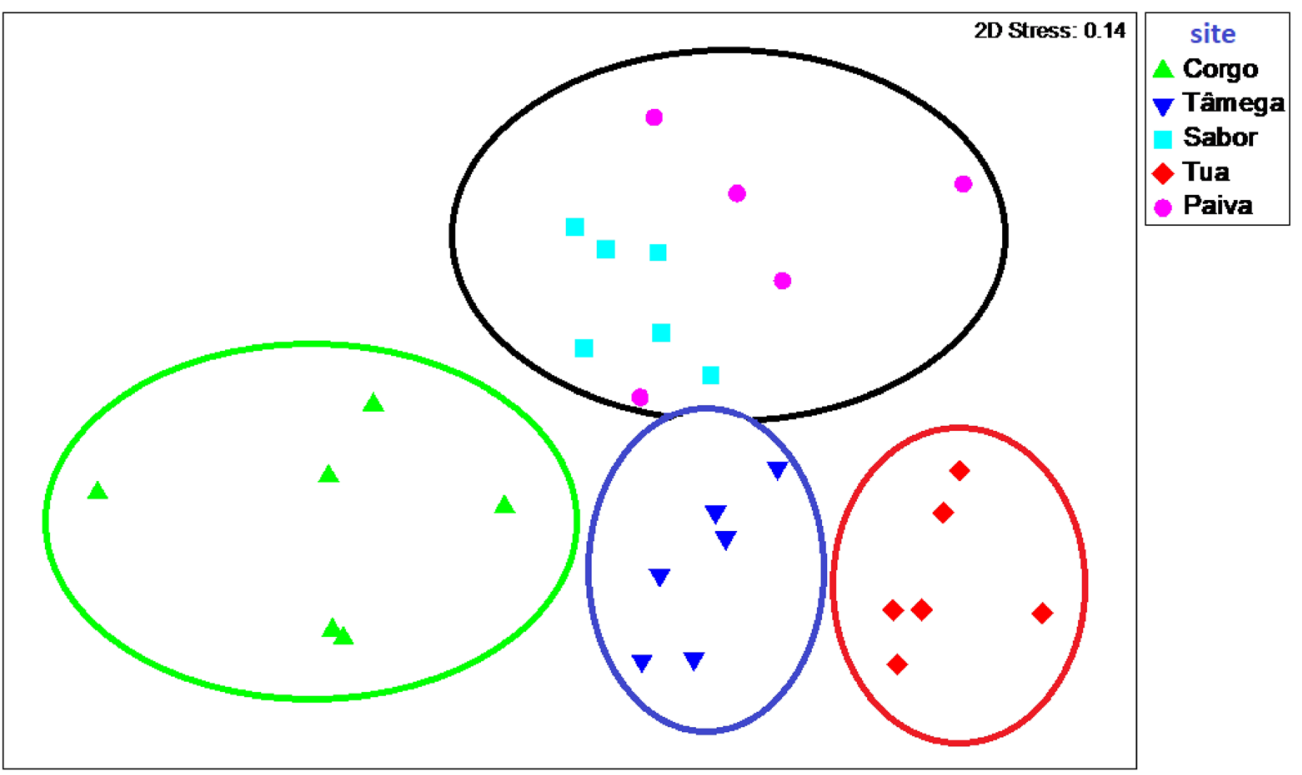

FIGURE 2 Non-metric multidimensional scaling (nMDS) of the fish communities sampled in the five sites from 6 December 2016 to 4 April 2017
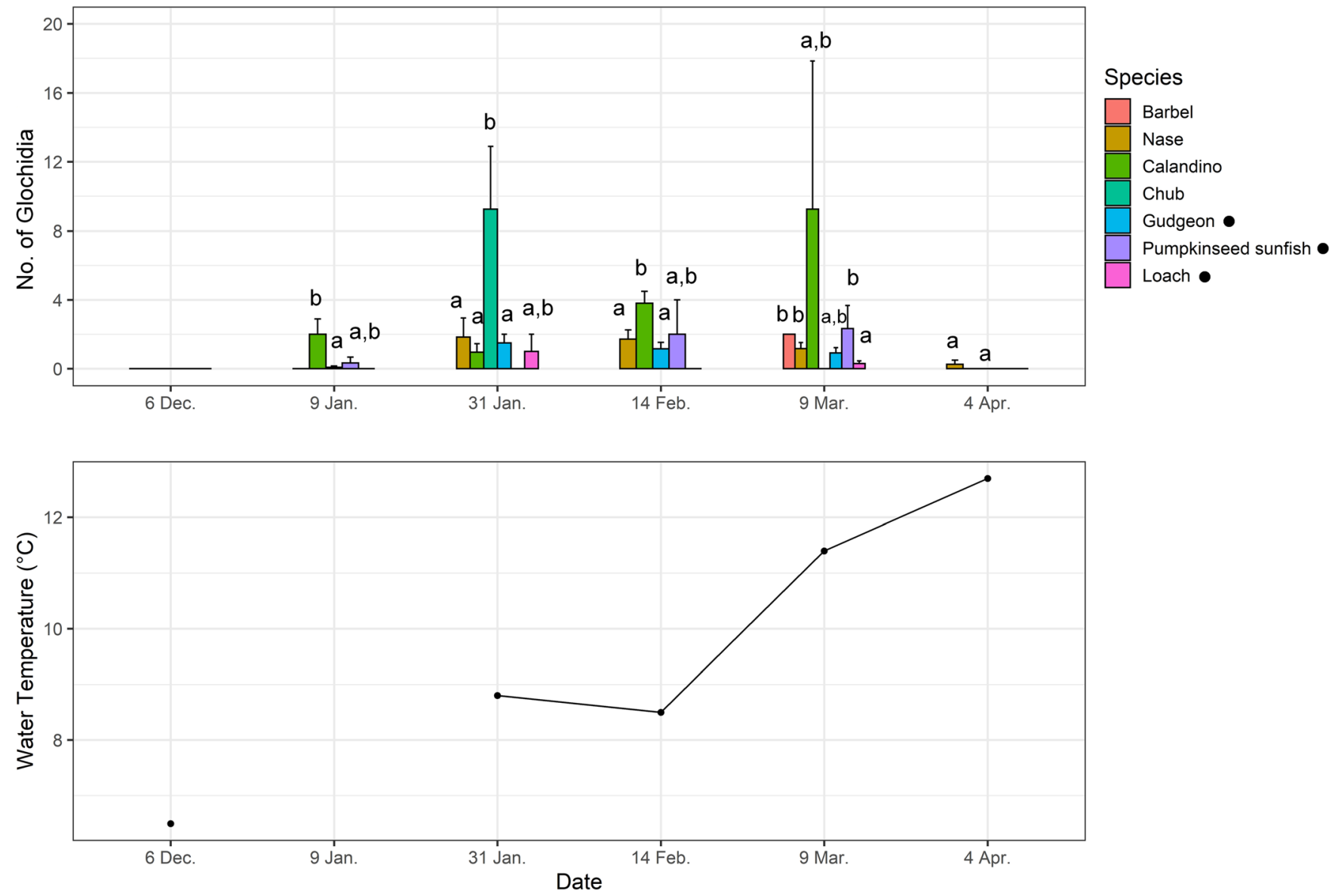

FIGURE 3 Average number (+SD) of Anodonta anatina glochidia for each fish species by date in the Corgo River. Different letters indicate significant differences $(P<0.05)$; each date should be considered independently; $\bullet$, non-native species. The water temperature $\left({ }^{\circ} \mathrm{C}\right)$ for each date is also shown

The number of barbel caught was very low, and this species only started to appear on 9 March (Figure 3). In the Paiva River, chub had the highest glochidial load on all sampling dates, followed by calandino, nase, and barbel. The maximum average was approximately six glochidia per fish (Figure 4). In the Tâmega River, chub and barbel had the highest glochidial loads, with the maximum average reaching approximately 

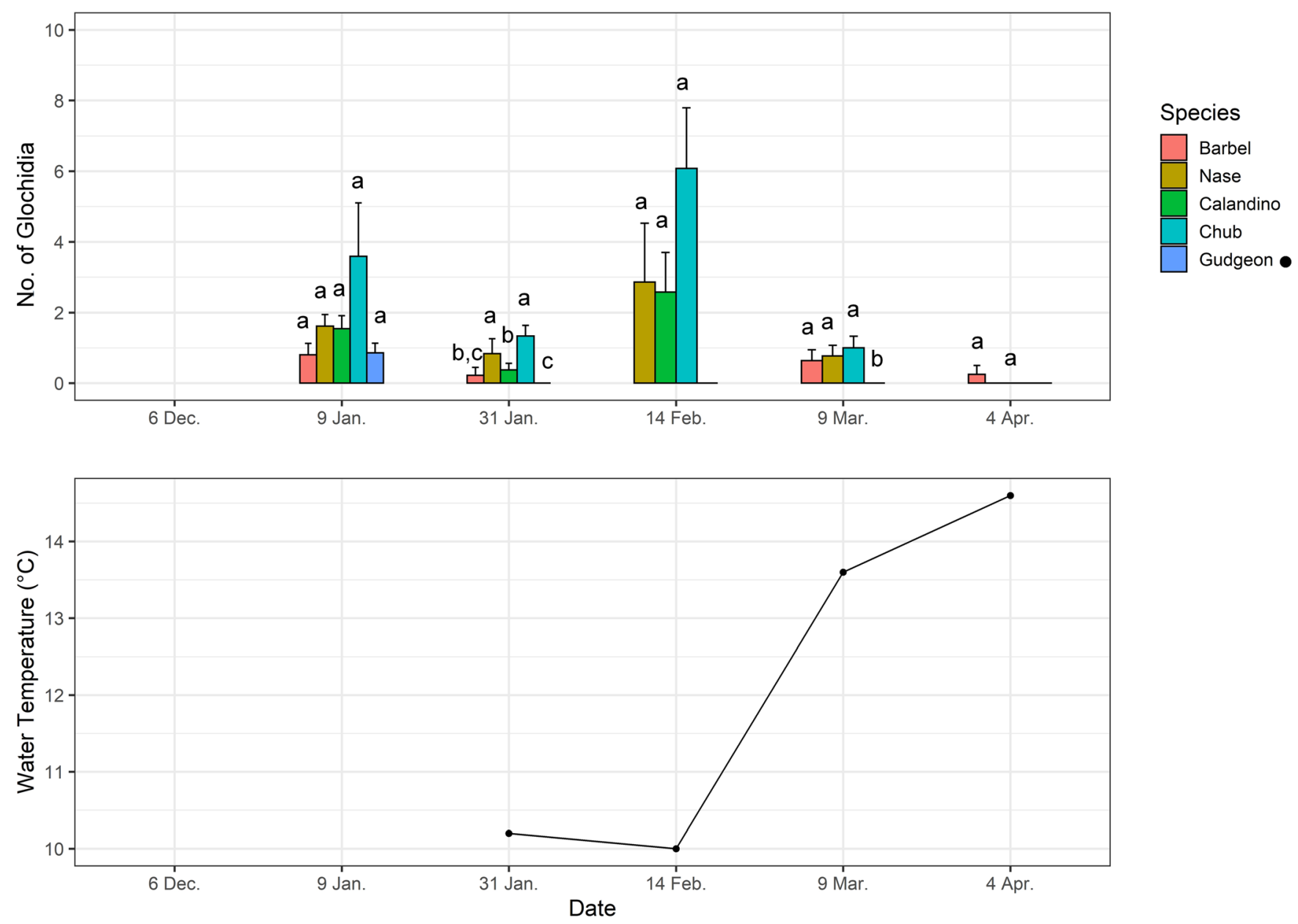

FIGURE 4 Average number (+SD) of Anodonta anatina glochidia for each fish species by date in the Paiva River. Different letters indicate significant differences $(P<0.05)$; each date should be considered independently; $\bullet$, non-native species. The water temperature $\left({ }^{\circ} \mathrm{C}\right)$ for each date is also shown

45 glochidia per fish, followed by calandino, nase, and pumpkinseed sunfish. Gudgeon also contained glochidia, although in much smaller numbers (Figure 5). In the Sabor River, the highest values were found in chub, barbel, and pumpkinseed sunfish on all sampling dates, with a maximum average of approximately 45 glochidia per fish (Figure 6). In the Tua River, chub and calandino had the highest values on almost every sampling date, followed by nase, barbel, and Alburnus alburnus (common bleak), with no glochidia found in Gambusia holbrooki (eastern mosquitofish). The maximum average was up to 16 glochidia per fish (Figure 7). The prevalence (i.e. percentage of fishes with glochidia attached) was highest between 9 January and 9 March, at all sampling sites, reaching $100 \%$ in most cases. The Tâmega and Sabor rivers had the highest prevalence and infestation rates, calculated as the total number of glochidia divided by the total number of fish. More detailed results on water temperature $\left({ }^{\circ} \mathrm{C}\right)$, fish species, average number of glochidia counted for each fish species, prevalence, and infestation rates can be found in Table S1.

When comparing the observed counts of fish infested with glochidia and the expected counts based on the number of fish species collected in the field, A. anatina showed no preference for a specific fish host in all rivers (Corgo, $G=8.23, P=0.08$; Paiva, $G=6.82, P=0.08$; Tua, $G=0.104, P=0.99$; Tâmega, $G=0.77$, $P=0.98$; and Sabor, $G=4.24, P=0.64$ ).

Correlations between the number of glochidia and the size of the fish were found on 31 January (for the Tâmega and Sabor rivers) and on 14 February (for the Corgo, Paiva, and Tua rivers), dates on which the maximum number of glochidia were observed. Positive correlations were found in the Paiva $\left(r^{2}=0.37, P=0.03\right)$, Tâmega $\left(r^{2}=0.39\right.$, $P<0.01)$, Tua $\left(r^{2}=0.25, P=0.01\right)$, and Sabor $\left(r^{2}=0.29, P=0.01\right)$ rivers (Figure 8).

The mean abundance of $A$. anatina was lowest in the Paiva River, with 2.67 ind. CPUE, followed by the Tua, Corgo, and Sabor rivers, with 7.50, 10.33, and 11.83 ind. CPUE, respectively. The Tâmega River had the highest abundance, with 33 ind. CPUE. Significant differences in the abundance of A. anatina were found between the Tâmega River and all other sites, and between the Paiva River and the Sabor and Tua rivers $\left(\chi^{2}=18.44, P=0.001\right)$. In the Sabor, Tâmega, and Tua rivers A. anatina co-occurs with Unio delphinus (Spengler, 1793); it also co-occurs with Potomida littoralis (Cuvier, 1798) in the Sabor and Tua rivers. A positive correlation between the abundance 

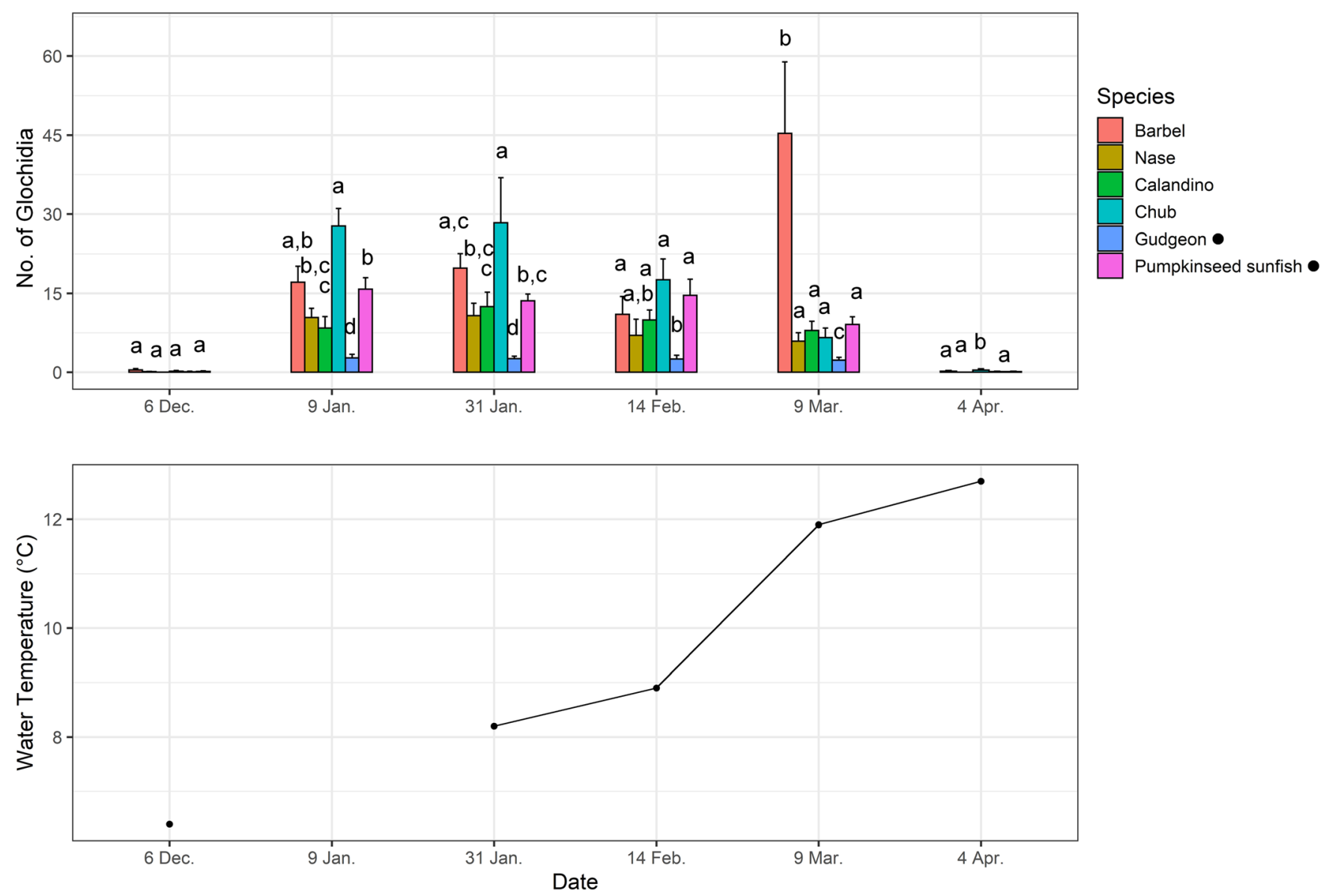

FIGURE 5 Average number (+SD) of Anodonta anatina glochidia for each fish species by date in the Tâmega River. Different letters indicate significant differences $(P<0.05)$; each date should be considered independently; $\bullet$, non-native species. The water temperature $\left({ }^{\circ} \mathrm{C}\right)$ for each date is also shown

of $A$. anatina and the number of glochidia was also found $(z=3.63$, $P<0.001)$.

\section{4 | DISCUSSION}

\subsection{Ecological hosts of Anodonta anatina}

Fish communities at the different sites were distinguished mainly by the presence or absence of non-native species, with native species, apart from the calandino, being ubiquitous in all sites. The eastern mosquitofish and common bleak were present only in the Tua River. In the Paiva River, the only non-native species found was the Pyrenean gudgeon, which was absent in the Tua River. Cobitis paludica (southern Iberian spined loach) was only present in the Corgo and Sabor rivers. These results were in accordance with what was expected for the native Iberian fish fauna, where the most common species in temperate basins such as the Douro were barbels, nases, and chubs (Clavero, Hermoso, Aparicio, \& Godinho, 2013). Contrary to the findings of Clavero et al. (2013), however, the number of nonnative species was higher than the number of native species, which can be explained by the scenario of biotic homogenization observed throughout the Iberian Peninsula (Clavero \& García-Berthou, 2006). No major differences were observed over time as none of the fish species found was migratory. Thus, the fish communities in the five rivers appear to remain stable in their composition over time.

A clear temporal pattern in glochidial loads, with a peak from the end of January until the middle of February, was found at all sites. Blažek and Gelnar (2006) studied the presence of glochidia of A. anatina, Anodonta cygnea (Linnaeus, 1758), Unio pictorum (Linnaeus, 1758), and Unio tumidus (Retzius, 1788) in several fish species in two rivers of the Czech Republic and found clear temporal differences, which were attributed to the influence of water temperature and intrinsic reproductive behaviour. These authors found glochidia from the genus Anodonta predominantly in the coldest months of the year, from October to May. Their results suggest that the occurrence of Anodonta glochidia is probably restricted to a maximum temperature of $14^{\circ} \mathrm{C}$. Our results were consistent with those found by Blažek and Gelnar (2006), with the maximum number of glochidia found between January and March, with corresponding temperatures of 6.6 and $13.6^{\circ} \mathrm{C}$. Dartnall and Walkey (1979) also observed glochidia from A. cygnea in Great Britain from December to May, with $100 \%$ of the hosts of each species infected during winter, and with large reductions in May. 

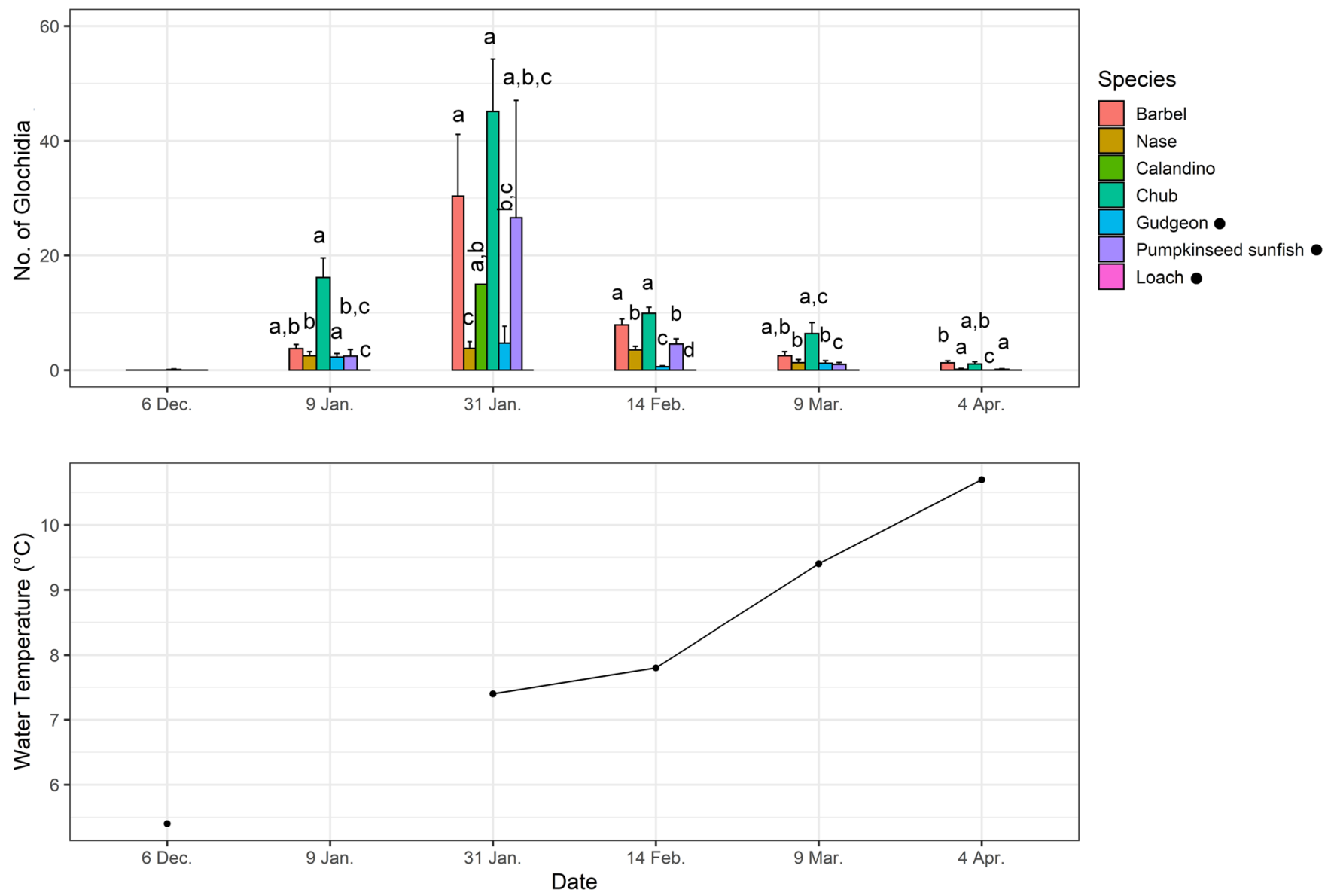

FIGURE 6 Average number (+SD) of Anodonta anatina glochidia for each fish species by date in the Sabor River. Different letters indicate significant differences $(P<0.05)$; each date should be considered independently; $\bullet$, non-native species. The water temperature $\left({ }^{\circ} \mathrm{C}\right)$ for each date is also shown

The northern Iberian chub and Iberian barbel were found to be the most suitable hosts presenting the highest glochidial loads, with only slight variations depending on the site. Almost all native fish species were successfully infested by glochidia together with the nonnative pumpkinseed sunfish, Pyrenean gudgeon, and the common bleak. Therefore, the results suggest that $A$. anatina could potentially infect any species provided that it is available in the river. In general, however, the non-native species carried a lower number of glochidia per fish than were found on native species. The differences observed among host species may result from differences in behaviour and microhabitat preferences between fish species. For example, the pumpkinseed sunfish is a very territorial species, especially during its reproductive season, when they build nests near the banks where most mussels are found (Hinzmann et al., 2013; Miller, 1963). By contrast, Pseudochondrostoma duriense (northern straight-mouth nase) prefers microhabitats with a higher current velocity, and usually occurs further away from the river banks, thus lowering the chance of being infested by A. anatina glochidia (authors' observation). Modesto et al. (2018) verified an association between several mussel species and the family Cyprinidae. In the Iberian Peninsula, most species belong to this family, and as they are associated with the benthos, they are more prone to infestation given their close relationship with the preferred habitat of freshwater mussels. Although almost all species were infested, this does not necessarily mean that every host species will be suitable and that the transformation into juveniles will be successful. Many glochidia may be 'wasted' on hosts that can be considered 'dead ends', such as the pumpkinseed sunfish.

Some studies on other freshwater mussel species showed that the probability of host fish infestation, when considering the number of glochidia per gram or length in $\mathrm{cm}$, was higher in smaller fishes and in those infested for the first time, owing to the acquired immunity of previously infested fish (Dodd, Barnhart, Rogers-Lowery, Fobian, \& Dimock, 2006; O'Connell \& Neves, 1999; Watters \& O'Dee, 1996). On the one hand, no correlations were observed between the size of the host fish and the number of glochidia per gram (Figures S1 to S5). On the other, a positive correlation was found at every site between the number of $A$. anatina glochidia and the size of the fish host, except in the Corgo River. This may be because most glochidia were mainly found on the external part of the host's body, especially on the fins. Thus, larger hosts imply higher surface areas, thereby increasing the probability of infestation. These results are in accordance with other studies that show similar correlations (Blažek \& Gelnar, 2006); however, Donrovich et al. (2017) found that the metamorphosis success rate of $A$. anatina glochidia was significantly reduced and declined on 

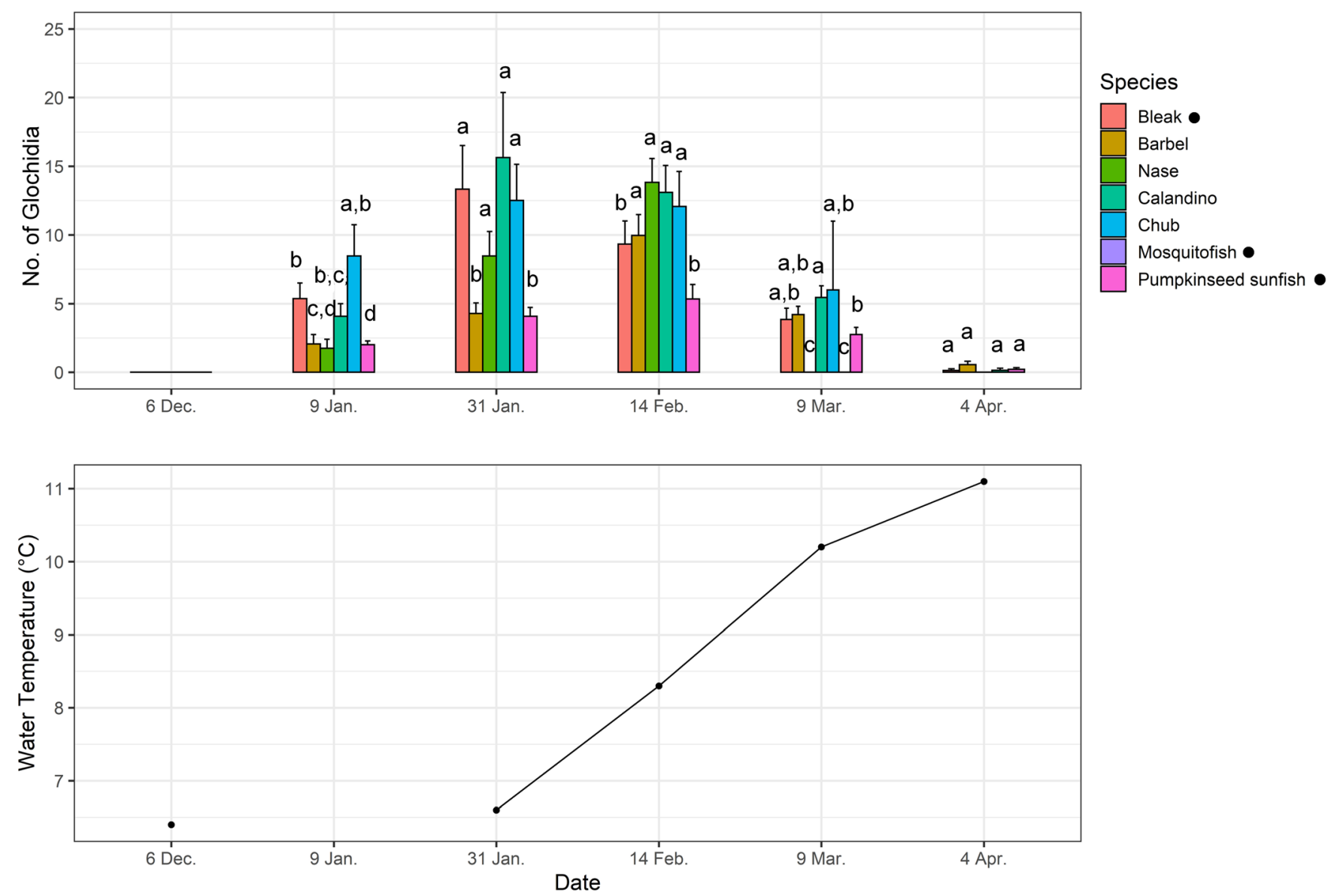

FIGURE 7 Average number (+SD) of Anodonta anatina glochidia for each fish species by date in the Tua River. Different letters indicate significant differences $(P<0.05)$; each date should be considered independently; $\bullet$, non-native species. The water temperature $\left({ }^{\circ} \mathrm{C}\right)$ for each date is also shown

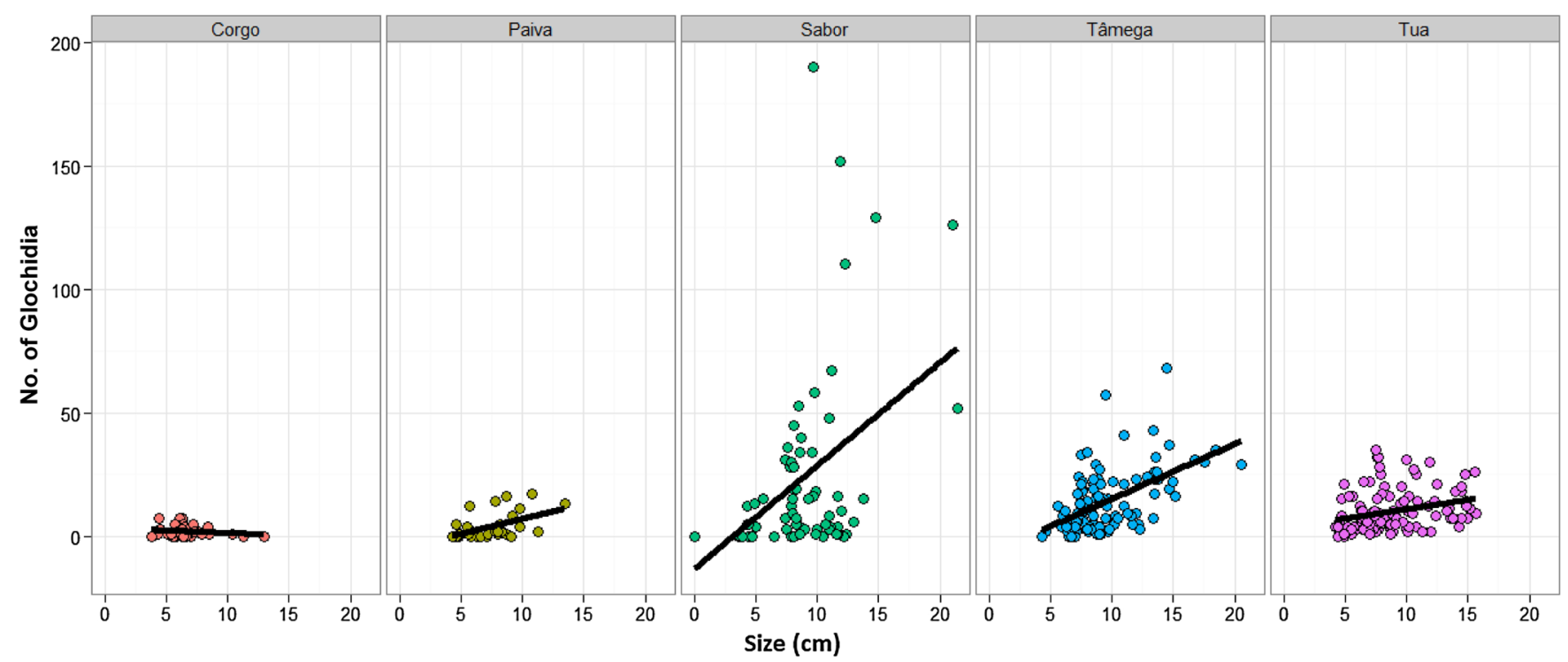

FIG URE 8 Number of glochidia of Anodonta anatina on 31 January 2017 (Tâmega and Sabor rivers) and 14 February 2017 (Corgo, Paiva, and Tua rivers) (maximum infestation) per fish size at the five different sites 
hosts that had previously been exposed to other mussel species. This effect might be implicated in the glochidial loads observed, because A. anatina exists in sympatry with other mussel species (e.g. P. littoralis and $U$. delphinus) at some of the study sites. In addition, the variation in the number of glochidia found among sites was correlated with the abundance of $A$. anatina at each location. As expected, a densitydependent effect was found, in which sites with a higher abundance of $A$. anatina adults (i.e. Tâmega, Tua, and Sabor) also contained fish with higher glochidial loads.

It is important to note that when determining potential hosts, the glochidial load should not be the only factor considered, even if the glochidia are capable of infesting multiple species, including nonnative fishes, as the transformation rate often varies from species to species. Douda et al. (2013), using fish species in the Czech Republic and Portugal, showed that even if A. anatina glochidia could infest a large number of host species, the transformation rate was much higher in native than in non-native species. In the laboratory, Douda et al. (2013) observed that the host with the highest glochidial loads was Salmo trutta fario (Linnaeus, 1758) (the brown trout), followed by chub and calandino; however, the highest transformation rates were found in nase and chub, with rates of 56.4 and $44.1 \%$, respectively. For the non-native species, no glochidia infested gudgeon and pumpkinseed sunfish, contrary to what we observed in situ. If the transformation rates are zero or very low in these species, they could function as a dead-end for the glochidia, as these larvae are not going to develop into juveniles (Moore, Collier, \& Duggan, 2019; Tremblay, Morris, \& Ackerman, 2016). In the present scenario, where non-native species are ubiquitous, it is important to note that these alterations in the fish communities (i.e. homogenization owing to the disappearance of native species and the introduction of non-native species) may lead to changes in the glochidia-host relationship, in which non-native species are generally not viable hosts for freshwater mussels (but see Huber and Geist (2019) and further discussion below).

\section{2 | Conservation implications}

Given the current biotic homogenization scenario of the fish communities in the Iberian Peninsula and many other locations (Clavero \& García-Berthou, 2006; Rahel, 2000), the absence of a shared evolutionary history might also impede the successful utilization of these non-native fish species as hosts by Iberian freshwater mussel species. Non-native fishes whose evolutionary history originates from an ecosystem where they were exposed to a great number of parasites might have spent more resources on their immune system, potentially hindering glochidial infestation. In addition, native mussels might also not have effective mechanisms to use this new resource (Douda et al., 2013). Moreover, the morphology of the glochidia or even the infestation strategy (e.g. if the glochidia are expelled to the water column or if the hosts are attracted, among others) might not be adapted to the behaviour of non-native fish species, making the infestation more difficult. The reverse situation is also possible, however, as non-native fish species might not possess an effective immune response or have a similar behaviour to the native fish species, facilitating the infestation (Douda, 2015; Douda et al., 2013). For example, Huber and Geist (2019) found that, of the 10 fish species tested in the laboratory, the non-native species $C$. idella was the second most suitable host. Freshwater mussels that use more than one fish host species, such as A. anatina, generally show great variation regarding the infestation and success of juvenile mussel excystment. Huber and Geist (2019) hypothesized that this is a very successful strategy for optimal dispersal and survival of the glochidia and juvenile mussels, because it allows the use of a broader fish diversity to maximize distribution and fitness. In addition, the different and species-specific durations of the metamorphosis phase, together with distinct host dispersal patterns and habitat preferences, also contribute to reducing the risk of mortality for offspring. This may be particularly crucial in short-lived species such as A. anatina, compared with host specialists such as Margaritifera margaritifera (Linnaeus, 1758), with lifespans of more than 100 years (Huber \& Geist, 2019).

Data on the infestation intensity and ecological hosts in the field are almost non-existent. This lack of data is problematic because for any conservation effort to be successful, knowledge about the basic ecology of the target organisms is necessary. In the case of freshwater mussels, and given their complicated life cycle, host specificity is a key factor for their survival and detailed information on this aspect is crucial for the success of any future management measure devoted to their conservation (Ferreira-Rodríguez et al., 2019). This study should be considered, therefore, as a first step. The data gathered need to be complemented with future studies that evaluate the possibility of a coextinction event occurring that involve these organisms, including the assessment of possible threats that can affect the glochidia-host relationship, and the spatial patterns and evolutionary dynamics associated with this relationship. In addition, the information reported here could also be useful for delimiting the conservation units of freshwater mussels (and their most effective host fish species), as it lays the groundwork for identifying appropriate hosts in situ at various times of the year, and allows the identification of locations of particular interest where mussels and fish hosts exist in sympatry. In conclusion, the conservation of freshwater mussels can only be effective if their host fish populations are in good condition. For A. anatina, and other unionid species, native fish species appear to be the major hosts, so their protection is fundamentally important.

\section{ACKNOWLEDGEMENTS}

This work was supported by the Fundação para a Ciência e Tecnologia (FCT), project 3599 'Promote the Scientific Production and Technological Development and Thematic 3599-PPCDT' by European Regional Development Fund (FEDER) as part of the project FRESHCO 'Multiple implications of invasive species on Freshwater Mussel coextinction processes' (contract: PTDC/AGRFOR/1627/2014). FCT also support MLL with a doctoral grant (SFRH/BD/115728/2016). We acknowledge the two anonymous referees for the helpful suggestions that improved the clarity of our manuscript. 


\section{ORCID}

Ana Rita Dias (D) https://orcid.org/0000-0001-6200-5366

Manuel Lopes-Lima (D) https://orcid.org/0000-0002-2761-7962

Ronaldo Sousa (iD https://orcid.org/0000-0002-5961-5515

\section{REFERENCES}

Alencoão, A. M. P., \& Pacheco, F. A. L. (2006). Infiltration in the Corgo river basin (northern Portugal): Coupling water balances with rainfall-runoff regressions on a monthly basis. Hydrological Sciences Journal, 51, 989-1005. https://doi.org/10.1623/hysj.51.6.989

Almaça, C. (1995). Freshwater fish and their conservation in Portugal. Biological Conservation, 72, 125-127. https://doi.org/10.1016/00063207(94)00075-2

Anderson, M. J. (2001). A new method for non-parametric multivariate analysis of variance. Austral Ecology, 26, 32-46. https://doi.org/10. 1111/j.1442-9993.2001.01070.pp.x

Anderson, M. J., Gorley, R. N., \& Clarke, K. R. (2008). PERMANOVA+ for PRIMER: Guide to software and statistical methods. Plymouth: PRIMER-E.

Barnhart, M. C., Haag, W. R., \& Roston, W. N. (2008). Adaptations to host infection and larval parasitism in Unionoida. Journal of the North American Benthological Society, 27, 370-394. https://doi.org/10.1899/ 07-093.1

Bauer, G. (2001). Framework and driving forces for the evolution of naiad life histories. In G. Bauer, \& K. Waechtler (Eds.), Ecology and evolution of the freshwater mussels Unionoida (pp. 233-255). Berlin Heidelberg: Springer.

Blažek, R., \& Gelnar, M. (2006). Temporal and spatial distribution of glochidial larval stages of European unionid mussels (Mollusca: Unionidae) on host fishes. Folia Parasitologica, 53, 98-106. https://doi. org/10.14411/fp.2006.013

Brodie, J. F., Aslan, C. E., Rogers, H. S., Redford, K. H., Maron, J. L., Bronstein, J. L., \& Groves, C. R. (2014). Secondary extinctions of biodiversity. Trends in Ecology \& Evolution, 29, 664-672. https://doi.org/10. 1016/j.tree.2014.09.012

Claro, A. (2010). Estudo de populações de mexilhão de rio (Margaritifera margaritífera L.): Análise da qualidade ecológica de ecossistemas lóticos da bacia hidrográfica do Rio Tua (NE Portugal) (Masters thesis). Instituto Politécnico de Bragança, Portugal.

Clavero, M., \& García-Berthou, E. (2006). Homogenization dynamics and introduction routes of invasive freshwater fish in the lberian Peninsula. Ecological Applications, 16, 2313-2324. https://doi.org/10.1890/ 1051-0761(2006)016[2313:hdairo]2.0.co;2

Clavero, M., Hermoso, V., Aparicio, E., \& Godinho, F. N. (2013). Biodiversity in heavily modified waterbodies: Native and introduced fish in Iberian reservoirs. Freshwater Biology, 58, 1190-1201. https://doi.org/ 10.1111/fwb.12120

Ćmiel, A. M., Zając, K., Lipińska, A. M., \& Zając, T. (2018). Glochidial infestation of fish by the endangered thick-shelled river mussel Unio crassus. Aquatic Conservation: Marine and Freshwater Ecosystems, 28, 535-544. https://doi.org/10.1002/aqc.2883

Colwell, R. K., Dunn, R. R., \& Harris, N. C. (2012). Coextinction and persistence of dependent species in a changing world. Annual Review of Ecology, Evolution, and Systematics, 43, 183-203. https://doi.org/10. 1146/annurev-ecolsys-110411-160304

Council of the European Communities (2000). Directive 2000/60/EC of the European Parliament and of the Council of 23 October 2000 establishing a framework for Community action in the field of water policy. Official Journal of the European Communities, L327, 1-73.

Dartnall, H. J. G., \& Walkey, M. (1979). The distribution of glochidia of the Swan mussel Anodonta cygnea (Mollusca) on the three-spined stickleback Gasterosteus aculeatus (Pisces). Journal of Zoology, 189, 31-37.
Dodd, B. J., Barnhart, M. C., Rogers-Lowery, C. L., Fobian, T. B., \& Dimock, R. V. (2006). Persistence of host response against glochidia larvae in Micropterus salmoides. Fish \& Shellfish Immunology, 21, 473-484. https://doi.org/10.1016/j.fsi.2006.02.002

Donrovich, S. W., Douda, K., Plechingerová, V., Rylková, K., Horký, P., Slavík, O., ... Sousa, R. (2017). Invasive Chinese pond mussel Sinanodonta woodiana threatens native mussel reproduction by inducing cross-resistance of host fish. Aquatic Conservation: Marine and Freshwater Ecosystems, 27, 1325-1333. https://doi.org/10.1002/aqc. 2759

Douda, K. (2015). Host-dependent vitality of juvenile freshwater mussels: Implications for breeding programs and host evaluation. Aquaculture, 445, 5-10. https://doi.org/10.1016/j.aquaculture.2015.04.008

Douda, K., Lopes-Lima, M., Hinzmann, M., Machado, J., Varandas, S., Teixeira, A., \& Sousa, R. (2013). Biotic homogenization as a threat to native affiliate species: Fish introductions dilute freshwater mussel's host resources. Diversity and Distributions, 19, 933-942. https://doi. org/10.1111/ddi.12044

Douda, K., Vrtílek, M., Slavík, O., \& Reichard, M. (2011). The role of host specificity in explaining the invasion success of the freshwater mussel Anodonta woodiana in Europe. Biological Invasions, 14, 127-137. https://doi.org/10.1007/s10530-011-9989-7

Dunn, R. R. (2005). Modern insect extinctions, the neglected majority. Conservation Biology, 19, 1030-1036. https://doi.org/10.1111/j.15231739.2005.00078.x

Dunn, R. R., Harris, N. C., Colwell, R. K., Koh, L. P., \& Sodhi, N. S. (2009). The sixth mass coextinction: Are the most endangered species parasites and mutualists? Proceedings of the Royal Society B, 276, 3037-3045. https://doi.org/10.1098/rspb.2009.0413

Ferreira-Rodríguez, N., Akiyama, B. Y., Aksenova, O., Araujo, R., Barnhart, C., Bespalaya, Y., ... Vaughn, C. C. (2019). Research priorities for freshwater mussel conservation assessment. Biological Conservation, 231, 77-87. https://doi.org/10.1016/j.biocon.2019. 01.002

Froufe, E., Sobral, C., Teixeira, A., Sousa, R., Varandas, S., Aldridge, D. C., \& Lopes-Lima, M. (2014). Genetic diversity of the pan-European freshwater mussel Anodonta anatina (Bivalvia: Unionoida) based on CO1: New phylogenetic insights and implications for conservation. Aquatic Conservation: Marine and Freshwater Ecosystems, 24, 561-574. https:// doi.org/10.1002/aqc.2456

Graff, D. L. (2007). Palearctic freshwater mussel (Mollusca: Bivalvia: Unionoida) diversity and the comparatory method as a species concept. Proceedings of the Academy of Natural Sciences of Philadelphia, 156, 71-88. https://doi.org/10.1635/0097-3157(2007)156[71:PFM $\mathrm{MBU}] 2.0 . \mathrm{CO} ; 2$

Haag, W. R., \& Warren, M. L. (1997). Host fishes and reproductive biology of 6 freshwater mussel species from the Mobile Basin, USA. Journal of the North American Benthological Society, 16, 576-585. https://doi. org/10.2307/1468145

Harrell, F. E., with contributions from Charles Dupont and many others. (2015). Hmisc: Harrell Miscellaneous. R Package Version 3.16-0. http://CRAN.R-project.org/package=Hmisc

Hinzmann, M., Lopes-Lima, M., Teixeira, A., Varandas, S., Sousa, R., Lopes, A., ... Machado, J. (2013). Reproductive cycle and strategy of Anodonta anatina (L., 1758): Notes on hermaphroditism. Journal of Experimental Zoology Part A, 319, 378-390. https://doi.org/10.1002/jez. 1801

Huber, V., \& Geist, J. (2019). Host fish status of native and invasive species for the freshwater mussel Anodonta anatina (Linnaeus, 1758). Biological Conservation, 230, 48-57. https://doi.org/10.1016/j.biocon. 2018.12.007

Koh, L. P., Dunn, R. R., Sodhi, N. S., Colwell, R. K., Proctor, H. C., \& Smith, V. S. (2004). Species coextinctions and the biodiversity crisis. Science, 305, 1632-1634. https://doi.org/10.1126/science. 1101101 
Lopes-Lima, M. (2014). Anodonta anatina. The IUCN Red List of Threatened Species https://doi.org/10.2305/IUCN.UK.2014-1.RLTS. T155667A21400363.en. [10 July 2017]

Lopes-Lima, M., Burlakova, L. E., Karatayev, A. Y., Mehler, K., Seddon, M., \& Sousa, R. (2018). Conservation of freshwater bivalves at the global scale: Diversity, threats and research needs. Hydrobiologia, 810, 1-14. https://doi.org/10.1007/s10750-017-3486-7

Lopes-Lima, M., Sousa, R., Teixeira, A., Varandas, S., Riccardi, N., Aldridge, D. C., \& Froufe, E. (2016). Newly developed microsatellite markers for the pan-European duck mussel, Anodonta anatina: Revisiting the main mitochondrial lineages. Aquatic Conservation: Marine and Freshwater Ecosystems, 26, 307-318. https://doi.org/10.1002/ aqc. 2575

Lopes-Lima, M., Hinzmann, M., Teixeira, A., Varandas, S., Machado, J., Sousa, R., \& Froufe, E. (2016). The strange case of tetragenous Anodonta anatina. Journal of Experimental Zoology Part A, 325A, 52-56. https://doi.org/10.1002/jez.1995

Lopes-Lima, M., Teixeira, A., Froufe, E., Lopes, A., Varandas, S., \& Sousa, R. (2014). Biology and conservation of freshwater bivalves: Past, present and future perspectives. Hydrobiologia, 735, 1-13. https://doi.org/10. 1007/s10750-014-1902-9

Lydeard, C., Cowie, R. H., Ponder, W. F., Bogan, A. E., Bouchet, P., Clark, S. A., ... Thompson, F. G. (2004). The global decline of nonmarine molluscs. Bioscience, 54, 321-330. https://doi.org/10.1641/ 0006-3568(2004)054[0321:TGDONM]2.0.CO;2

Meira, A., Lopes-Lima, M., Varandas, S., Teixeira, A., Arenas, F., \& Sousa, R. (2019). Invasive crayfishes as a threat to freshwater bivalves: Interspecific differences and conservation implications. Science of the Total Environment, 649, 938-948. https://doi.org/10.1016/j.scitotenv.2018. 08.341

Miller, H. (1963). The behaviour of the Pumpkinseed Sunfish, Lepomis gibbosus (Linnaeus), with notes on the behaviour of other species of Lepomis and the Pigmy Sunfish, Elassoma everglei. Behaviour, 22, 88-150. https://doi.org/10.1163/156853963X00329

Modesto, V., Ilarri, M., Souza, A. T., Lopes-Lima, M., Douda, K., Clavero, M., \& Sousa, R. (2018). Fish and mussels: Importance of fish for freshwater mussel conservation. Fish and Fisheries, 19, 224-259. https://doi.org/10.1111/faf.12252

Moore, T. P., Collier, K. J., \& Duggan, I. C. (2019). Interactions between Unionida and non-native species: A global meta-analysis. Aquatic Conservation: Marine and Freshwater Ecosystems, 29, 1438-1451. https://doi.org/10.1002/aqc.3040

O'Connell, M. T., \& Neves, R. J. (1999). Evidence of immunological responses by a host fish (Ambloplites rupestris) and two non-host fishes (Cyprinus carpio and Carassius auratus) to glochidia of a freshwater mussel (Villosa iris). Journal of Freshwater Ecology, 14, 71-78. https:// doi.org/10.1080/02705060.1999.9663656

Perez, J. M., \& Palma, R. L. (2001). A new species of Felicola (Phthiraptera: Trichodectidae) from the endangered Iberian lynx: Another reason to ensure its survival. Biodiversity and Conservation, 10, 929-937. https:// doi.org/10.1023/A:1016688529572

Portilho, E. S. M. (2013). Avaliação da qualidade ecológica do rio Tâmega (Master Thesis). Faculdade de Ciências da Universidade do Porto, Portugal.

R Core Team (2017). R: A language and environment for statistical computing. Vienna, Austria: R Foundation for Statistical Computing. https:// www.R-project.org/

Rahel, F. J. (2000). Homogenization of fish faunas across the United States. Science, 288, 854-856. https://doi.org/10.1126/science.288. 5467.854

Rahel, F. J. (2002). Homogenization of freshwater faunas. Annual Review of Ecology and Systematics, 33, 291-315. https://doi.org/10.1146/ annurev.ecolsys.33.010802.150429
Silva, L. (2010). Avaliação da qualidade ecológica de sistemas lóticos da bacia hidrográfica do Rio Sabor (Bacia do Douro) (Masters thesis). Instituto Politécnico de Bragança, Portugal.

Sousa, R., Amorim, A., Sobral, C., Froufe, E., Varandas, S., Teixeira, A., \& Lopes-Lima, M. (2013). Ecological status of a Margaritifera margaritifera (Linnaeus, 1758) population at the southern edge of its distribution (River Paiva, Portugal). Environmental Management, 52, 1230-1238. https://doi.org/10.1007/s00267-013-0117-6

Sousa, R., Ferreira, A., Carvalho, F., Lopes-Lima, M., Varandas, S., \& Teixeira, A. (2018). Die-offs of the endangered pearl mussel Margaritifera margaritifera during an extreme drought. Aquatic Conservation: Marine and Freshwater Ecosystems, 28, 1244-1248. https://doi. org/10.1002/aqc.2945

Sousa, R., Nogueira, J. G., Ferreira, A., Carvalho, F., Lopes-Lima, M., Varandas, S., \& Teixeira, A. (2019). A tale of shells and claws: The signal crayfish as a threat to the pearl mussel Margaritifera margaritifera in Europe. Science of the Total Environment, 665, 329-337. https://doi. org/10.1016/j.scitotenv.2019.02.094

Sousa, R., Varandas, S., Cortes, R., Teixeira, A., Lopes-Lima, M., Machado, J., \& Guilhermino, L. (2012). Massive die-offs of freshwater bivalves as resource pulses. Annales de Limnologie - International Journal of Limnology, 48, 105-112. https://doi.org/10.1051/limn/ 2012003

Spooner, D. E., Xenopoulos, M. A., Schneider, C., \& Woolnough, D. A. (2011). Coextirpation of host-affiliate relationships in rivers: The role of climate change, water withdrawal, and host-specificity. Global Change Biology, 17, 1720-1732. https://doi.org/10.1111/j.13652486.2010.02372.x

Strayer, D. L., Downing, J. A., Haag, W. R., King, T. L., Layzer, J. B., Newton, T. J., \& Nichols, S. J. (2004). Changing perspectives on pearly mussels, North America's most imperilled animals. Bioscience, 54, 429-439. https://doi.org/10.1641/0006-3568(2004)054[0429: CPOPMN]2.0.CO;2

Taeubert, J. E., Gum, B., \& Geist, J. (2011). Host-specificity of the endangered thick-shelled river mussel (Unio crassus, Philipsson 1788) and implications for conservation. Aquatic Conservation: Marine and Freshwater Ecosystems, 22, 36-46. https://doi.org/10.1002/aqc.1245

Tremblay, M. E. M., Morris, T. J., \& Ackerman, J. D. (2016). Loss of reproductive output caused by an invasive species. Royal Society Open Science, 3, 150481. https://doi.org/10.1098/rsos.150481

Watters, G. T., \& O'Dee, S. H. (1996). Shedding of untransformed glochidia by fishes parasitized by Lampsilis fasciola Rafinesque, 1820 (Mollusca: Bivalvia: Unionidae): Evidence of acquired immunity in the field? Journal of Freshwater Ecology, 11, 383-389. https://doi.org/10.1080/ 02705060.1996.9664465

Wickham, H. (2009). ggplot2: Elegant graphics for data analysis. New York: Springer-Verlag.

\section{SUPPORTING INFORMATION}

Additional supporting information may be found online in the Supporting Information section at the end of this article.

How to cite this article: Dias AR, Teixeira A, Lopes-Lima M, Varandas S, Sousa R. From the lab to the river: Determination of ecological hosts of Anodonta anatina. Aquatic Conserv: Mar Freshw Ecosyst. 2020;30:988-999. https://doi.org/10.1002/ aqc.3328 